\title{
Specific futsal training program can improve the physical performance of futsal players
}

\author{
Ricardo Augusto Barbieri ${ }^{1}$ Alessandro Moura Zagatto ${ }^{2} \cdot$ Fabio Milioni $^{1}$ • \\ Fabio Augusto Barbieri ${ }^{2}$
}

Received: 3 February 2016/Accepted: 11 May 2016/Published online: 20 May 2016

(C) Springer-Verlag Italia 2016

\begin{abstract}
Purpose This study investigated the effects of 12-week of specific futsal training on body composition, oxygen uptake $\left(V \mathrm{O}_{2 \max }\right)$, anaerobic capacity, and agility of male semi-professional futsal players.

Methods Thirteen athletes were subjected to a 12-week program of specific training for futsal with the external load of sessions prescribed from rated perceived exertion. $V \mathrm{O}_{2 \max }$, agility, anaerobic index, and body composition were assessed before and after the 12-week training program.

Results The main findings were that the 12-week training period was able to significantly reduce the fat percentage of body composition $(-7.5 \%)$ and to improve the agility $(3.9 \%)$, aerobic capacity $(>7 \%)$, and anaerobic index (6-25\%).

Conclusions Based on these results, it can be concluded that a 12-week program of specific training for futsal with the external load of sessions prescribed from rated perceived exertion can significantly improve the body composition, agility and aerobic and anaerobic capacity of semi-professional futsal players.
\end{abstract}

Keywords Aerobic capacity - Repeated sprints . External load control · Agility · Body composition

Ricardo Augusto Barbieri

Barbieri_ef@hotmail.com

1 Department of Physical Education, UNESP- Univ Estadual Paulista, Rio Claro, Brazil

2 Department of Physical Education, UNESP- Univ Estadual Paulista, Bauru, Brazil

\section{Introduction}

Futsal presents specific demands for good physical performance [1-6], where oxidative phosphorylation is responsible for around $76 \%$ of all energy resynthesized in the match with the average of oxygen uptake around $48.6 \mathrm{~mL} \mathrm{~kg}^{-1} \mathrm{~min}^{-1}$, demonstrating that the aerobic metabolism may be a limiting factor in futsal; therefore, the development of this physical capacity is important for the athletes to achieve high performance in sports $[2,3]$.

Meanwhile, key moments of the match have a high intensity character with a short duration [3, 7, 8], mainly through repeated efforts at high intensity [9]. According to Castagna et al. [3], key moments during the match demonstrate high participation of anaerobic systems (3-4 shorts sprints with $20-30 \mathrm{~s}$ of rest), with average lactate concentration around $5.3 \mathrm{mmol} \mathrm{L}^{-1}$ and peaks of $80-85 \%$ relative to maximal concentration.

Different from futsal, other sports, such as soccer, present important information on the effects of sport specific training programs on physical performance [10]. In addition, De Oliveira Bueno and colleagues [11] indicated that Brazilian futsal players present lower performance in intermittent field tests compared to European players, which seems to indicate a lower quality of the training program of these athletes, either regarding the volume, intensity, duration, frequency, or even the manipulation of these parameters that comprise the periodization training. Thus, there is a gap regarding the effects of exercise training programs on aerobic and anaerobic conditioning of professional and semi-professional futsal athletes. The previous research has provided important information about futsal training, but it is primarily concerned with either the pre-season $[4,6]$, or analyzing short periods (3-4 weeks) of training during the 
competitive season $[5,6]$. This makes it difficult to understand the effects of periodization over longer training periods.

Knowledge of the effects of specific training programs for futsal could help coaches and trainers to organize the training periodization and establish the benefits expected from training. Thus, the aim of this study was to investigate the effects of 12-week of specific futsal training on the physical performance (aerobic and anaerobic) and body composition of semi-professional futsal players.

\section{Methods}

\section{Participants}

Thirteen male semi-professional futsal players (age $22 \pm 2$ years, body mass $74 \pm 11 \mathrm{~kg}$ and height $175 \pm 6 \mathrm{~cm}$ ) comprising three goalkeepers, two defenders, six wing midfielders, and two forwards/pivots were recruited. The athletes had been playing regional, state, and university futsal tournaments regularly for at least the previous 3 years, without a history of health problems and they signed a free and informed consent form approved by the local ethics committee.

The analysis with the $G^{*}$ Power software showed that a sample size of at least 12 individuals was needed for an $80 \%$ probability to detect a difference of $20 \%$ between two dependent measure for the primary outcome with a type I error of 0.05 , based on previously published data [12].

\section{Study design}

Subjects were assessed at two different moments, before the start of the training period (pre-training, T1) and after 12-week of training (post-training, T2). The T1 and T2 assessments were divided over 2 days with an interval of $48 \mathrm{~h}$. On the first day, measurements of body composition and maximal anaerobic power were performed through the Running-based Anaerobic Sprint Test (RAST) [13]. On the second day, agility through the Shuttle Run Test (SRT) [14] and aerobic parameters through the Shuttle Run Multistage $20 \mathrm{~m}$ Test (SRT20) [15] were assessed. The athletes were instructed not to engage in strenuous activity for $48 \mathrm{~h}$ prior to the assessments and to avoid extreme changes in the sleep and dietary profiles during the investigated period.

\section{Body composition}

Body mass was measured using an anthropometric scale (Balance Mechanics, Welmy, Brazil) with a precision of $100 \mathrm{~g}$ and height with a wooden stadiometer accurate to
$0.1 \mathrm{~cm}$. The skinfold thicknesses were measured in millimeters using a Cescorf ${ }^{\circledR}$ Premier Scientific skinfold caliper $\left(\right.$ Cescorf $^{\circledR}$, Porto Alegre, Rio Grande do Sul, Brazil). The folds were measured in the triceps, subscapular, suprailiac (supraspinatus), medial thigh and leg. The bone diameters between the epicondyles of the humerus and femur were determined using a metal pachymeter $\left(\right.$ Somet $^{\circledR}$, $150 \mathrm{~mm}$, Inox, Czech Republic) with a measuring scale of $0.1 \mathrm{~cm}$. The circumference measurements of the contracted arm and calf were performed using a flexible Gulick tape measure model $150 \mathrm{~cm}$ (Mabis ${ }^{\circledR}$, Waukegan, IL, USA).

The anthropometric measurements allowed the calculation of the body mass index, corporal density [16] and estimation of the percentage body fat. The body somatotype was estimated following Heath and Carter [17], and the anthropometric measurements were performed from the suggestions of Ross and Marfell-Jones [18]. To classify the somatotype of the athletes, a graphical analysis of somatotype clusters was performed according to the proposal of Heath and Carter [17]. This protocol demonstrates a good reliability test-rest (endomorph $=0.92$; mesomorph $=0.83$; ectomorph $=0.93$ ) [19]. For this, the coordinate points (vertical $-Y$; horizontal $-X$ ) were calculated as follows: $X=\mathrm{III}-\mathrm{I}$ and $Y=\mathrm{II}-(\mathrm{I}+\mathrm{III})$. Where I is the endomorph component, II is the mesomorph component, and III is the ectomorph component.

\section{Anaerobic parameters}

To assess the anaerobic power and fatigue index (FI), the Running Anaerobic Sprint Test (RAST) [13, 20] was used. The protocol consisted of six $35 \mathrm{~m}$ all out sprints with passive intervals of $10 \mathrm{~s}$ between the efforts. Furthermore, the procedure shows a high reliability (intraclass correlation coefficient $\sim 0.88$ ) and significant correlations with the Wingate test (peak power $r=0.46$; mean power $r=0.53$; fatigue index $r=0.63$ ) and 35, 50,100, 200, and $400 \mathrm{~m}$ performance scores $(p<0.05)[13]$. The test was performed on a futsal court, and the power output of each effort and FI was calculated using the equations: power output $=$ body mass $\times$ distance $^{2} \div$ time running $^{3} ; \quad F I=(100 \times($ total sprint time $\div$ ideal sprint time) $)-100$, where total sprint time is the sum of sprint times from all sprints and ideal sprint time is the number of sprints multiplied by the fastest sprint time $[12,19]$. From the power output of each effort, it was possible to determine the maximum and mean power output for each participant. In addition, the maximum speed of the athletes was determined from the first effort.

\section{Aerobic parameters}

To assess aerobic capacity, the Shuttle Run Multistage 20 $\mathrm{m}$ Test (SRT20) [15] was used. The test consists of a series 
of intermittent and progressive runs of $20 \mathrm{~m}$, starting at $8.5 \mathrm{~km} \mathrm{~h}^{-1}$ with increments of $0.5 \mathrm{~km} \mathrm{~h}^{-1}$ per minute (stages) until the impossibility of the subject to maintain the pre-stipulated speed. The test was performed on an indoor futsal court, properly marked and equipped. This protocol demonstrates a good test-retest reliability (intraclass correlation coefficient $=0.75)$ [21] and good concurrent validity in Brazilian young adults (men, $r=0.73$; women, $r=0.75$ ) [22]. The maximal aerobic capacity was estimated from the regression equation: $V \mathrm{O}_{2 \max }$ $\left(\mathrm{mL} \mathrm{kg}^{-1} \min ^{-1}\right)=(6 \times$ speed test $)-4.4$, where the speed test was defined as the speed achived in the last complete stage.

\section{Agility test}

Agility capacity was evaluated through the Shuttle Run Test (SRT) [14]. The test consists of two cones set out $9.14 \mathrm{~m}$ from each other, and two wooden blocks $(5 \mathrm{~cm} \times 5 \mathrm{~cm} \times 10 \mathrm{~cm})$ placed equidistant on the side of one of the cones. Ortega et al. [23] showed that the protocol has a good reliability with a concordance between testretest condition by the graphical analysis of Bland-Altman plots. Furthermore, the systematic error of the stopwatch in comparison with the photoelectric cells was $\sim 0.1 \mathrm{~s}$ $(p<0.01)$ [24]. The subject starts from the cone without the wooden blocks and sprints the $9.14 \mathrm{~m}$ twice to collect the wooden blocks and move them to the side of the starting cone as quickly as possible.

The blocks cannot be thrown, and the subject is required to place one or both legs beyond the demarcation line (cones) to validate their displacement. Every round is timed and ends when the volunteer passes the line in the second round and puts the block on the ground; the average of the two attempts was calculated to represent the performance measure.

\section{Training program and quantification of external load}

The athletes trained for 12-week, three to four times per week in evening sessions, reaching an average volume of $5.7 \mathrm{~h}$ per week. The training prescription of intensity and quantification of the external training load were performed based on the proposal of Foster et al. [25] in which the rated perceived exertion ( $\mathrm{RPE}-0$ to 10 ) was multiplied by the total volume of the session in minutes. It is important to highlight that the training program was proposed without interference of the researchers.

The training program coincided with the competitive period with a large number of games in the final week (four playoff matches). The training periodization was scheduled temporally in microcycles encompassing 7 days (1 week) and proposed mesocycles of 4-week periods with individual specific goals, of which the first was a base period, the second mesocycle covered specific preparation, and the third was the period when the main matches took place. Figure 1 shows the proposed load (external load) over weeks (A) and mesocycles (B).

During the monitored period, the majority of time spent in the training sessions had specific characteristics (Table 1) that can be classified as: Strength training (Strength); Regenerative (Reg); Endurance (End); Speed (Spe); Tactical (Tac); small-side-games (SG); Friendly matches (FMgames used for the preparation for competitive games); competitive matches (CM).

Strength training was performed in the circuit-training model by applying exercises with dumbbell, resistance bands, and functional training. During the session training, it was executed two to three set of exercises with 15-20 repetitions that included exercises for quadriceps, hamstrings, adductor, abductors, abs, triceps, biceps, chest, and upper and low back. Reg was composed by continuous jogging and/or walking and coordination exercises with ball control with low intensity (score 3-5 at the PSE). End training was performed with continuous and/or interval running with intensity between scores 7 and 9 at the PSE. Therefore, the goalkeeper performed specific exercises (jumps, changes in direction and specific defenses movements), the defenders performed
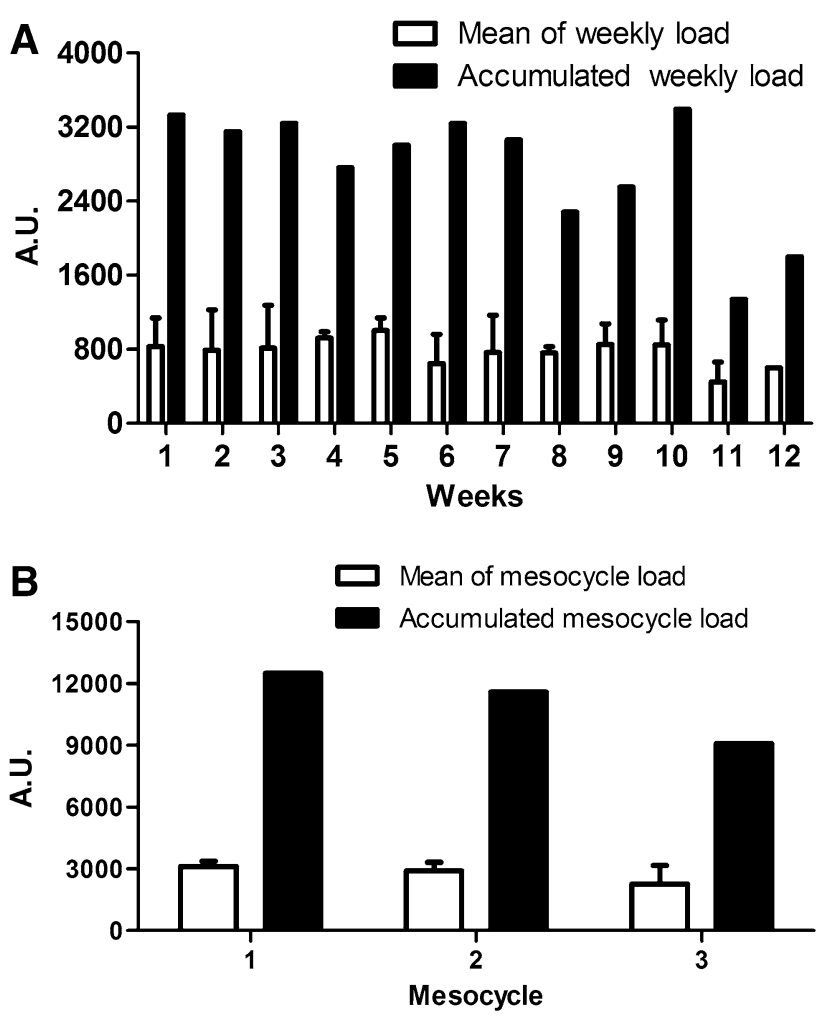

Fig. 1 Means and standard deviation of accumulated external load and microcycles (a) and mesocycles (b) 
Table 1 Distribution of activities during the 12-week of futsal specific training

\begin{tabular}{|c|c|c|c|c|c|c|c|}
\hline Week & Monday & Tuesday & Wednesday & Thursday & Friday & Saturday & Sunday \\
\hline 1 & End-Strength & Spe-Strength & Reg & Spe-Strength & & & \\
\hline 2 & Spe-Strength & End & Tac-Strength & Tac-Strength & & & \\
\hline 3 & SG-Strength & Reg & $\mathrm{CM}$ & End-Strength & & & \\
\hline 4 & Spe-Strength & SG-Strength & & Tac-Strength & & & \\
\hline 5 & Tac-Strength & Tac-Spe & & Tac & & & $\mathrm{CM}$ \\
\hline 6 & Reg & SG-Tac & Spe-Strength & Spe-SG-Strength & & & \\
\hline 7 & Spe-Strength & SG-Tac-Strength & $\mathrm{FM}$ & Tac-Strength & & & \\
\hline 8 & End-Strength & SG-Tac & FM & Spe-Tac & & & \\
\hline 9 & SG-Tac-Strength & Tac-Strength & & Tac-Strength & & & $\mathrm{CM}$ \\
\hline 10 & Spe-SG-Strength & Tac-Strength & & Tac-Strength & & & \\
\hline 11 & Tac & Tac & & Tac & & $\mathrm{CM}$ & \\
\hline 12 & $\mathrm{CM}$ & & $\mathrm{CM}$ & & & $\mathrm{CM}$ & \\
\hline
\end{tabular}

Strength dumbbell workout and functional training, Reg regenerative training, End endurance, Spe speed training, Tac tactical training, SG smallside-games, $F M$ friendly matches, $C M$ competitive matches

exercises with small changes of direction to simulate the man marking, wingers executed intense displacements followed shooting drills for finishing, and the forwards/pivots performed exercises to training ball protection, dribbling and shooting drills for finishing. Speed training was composed by sprints from 5 to $30 \mathrm{~m}$, with or without changes in direction and with or without ball control, whereas for Tac training, there was focus on the 2-2, 3-1 1-2-1, and 4-0 attacking systems and man marking and the variations on the zonal system to defending system. Small-side games was composed of games with the manipulation of the dimensions of the playing area, the number of participants (numerical superiority) and rules to achieve specifically the technical and tactical objectives as well as intensity proposed for the session.

\section{Statistical analysis}

Values are presented as mean \pm standard deviation. The normality and homogeneity of the data were confirmed using the Shapiro-Wilk and Levene tests, respectively. The effect size induced by training was calculated for all variables, and the paired student $t$ test was performed to compare variables before and after 12-week of training. In all cases, the level of significance was fixed at $p<0.05$.

\section{Results}

The effects of specific futsal training on body composition, aerobic and anaerobic parameters, and agility are shown in Table 2. After 12-week of training, there were no significant changes in body mass or the body mass index. However, the training program was effective in significantly reducing the percentage of body fat and significantly increasing the maximal speed in the $\mathrm{SRT}_{20}$ and $V \mathrm{O}_{2 \max }$, as well as significantly improving the average time of the two attempts in the SRT. Furthermore, the training program significantly increased the maximum, mean, and minimum power and the sprinting speed during the RAST, without changes in the fatigue index (Table 2).

Despite the changes in body composition, the estimated somatotype did not change significantly, with an average tendency of the endo mesomorph characteristic for both training periods (Fig. 2).

\section{Discussion}

The aim of this study was to investigate the effects of 12-week of specific futsal training on physical performance (aerobic and anaerobic) and body composition of semiprofessional futsal players. The main findings were that the 12-week training period was able to significantly reduce (paired student $t$ test) the fat percentage $(-7.5 \%)$ and to improve the agility $(3.9 \%)$, aerobic $(>7 \%)$, and anaerobic (6-25\%) parameters.

Since a systematic training program is well structured, it is expected to improve physical performance for the analyzed parameters. However, the study was innovative in analyzing the responses to a periodization which included the competition period, and few studies have explored this in futsal; in addition, the present study had a long training period (12-weeks), which is not common in such studies.

The athletes in this study presented an anthropometric profile similar to that in other studies of adult futsal players [2, 3, 9, 26, 27]. Despite the importance of anthropometric variables on sports performance, there are few studies that have found alterations in body composition across the 
Table 2 Values of body composition and anaerobic and aerobic parameters and agility before and after 12-week of futsal training

\begin{tabular}{|c|c|c|c|c|c|}
\hline & $\mathrm{T} 1$ & $\mathrm{~T} 2$ & $\mathrm{PC}(\%)$ & $p$ value & EF \\
\hline \multicolumn{6}{|l|}{ Body composition } \\
\hline Height (cm) & $175 \pm 6.54$ & $1.75 \pm 6.54$ & 0.00 & 1.00 & 0.01 \\
\hline Body mass (kg) & $74.16 \pm 11.66$ & $74.18 \pm 10.77$ & 0.19 & 0.96 & 0.01 \\
\hline $\mathrm{BMI}\left(\mathrm{kg} \mathrm{m}^{-2}\right)$ & $24.19 \pm 3.05$ & $24.20 \pm 2.79$ & 0.19 & 0.92 & 0.01 \\
\hline Percentage body fat $(\%)$ & $14.42 \pm 4.54$ & $13.56 \pm 3.44$ & -7.46 & 0.03 & 0.21 \\
\hline Lean body mass (kg) & $63.11 \pm 7.70$ & $64.21 \pm 8.50$ & 1.63 & 0.07 & 0.13 \\
\hline Endomorph & $3.72 \pm 1.42$ & $3.32 \pm 1.10$ & -6.99 & 0.08 & 0.31 \\
\hline Mesomorph & $4.68 \pm 1.23$ & $4.57 \pm 1.19$ & -2.17 & 0.31 & 0.09 \\
\hline Ectomorph & $1.84 \pm 1.10$ & $1.91 \pm 1.15$ & 3.80 & 0.45 & 0.06 \\
\hline \multicolumn{6}{|l|}{ Anaerobic parameters } \\
\hline Maximal power (W) & $569.97 \pm 117.67$ & $690.59 \pm 179.99$ & 25.55 & 0.03 & 0.81 \\
\hline Average power (W) & $452.22 \pm 60.06$ & $520.61 \pm 81.07$ & 18.97 & 0.01 & 0.97 \\
\hline Minimum power $(\mathrm{W})$ & $357.26 \pm 54.83$ & $418.31 \pm 48.16$ & 19.07 & 0.01 & 1.18 \\
\hline Fatigue index $(\%)$ & $6.60 \pm 9.04$ & $11.76 \pm 10.04$ & 25.31 & 0.66 & 0.25 \\
\hline Maximal speed $\left(\mathrm{m} \mathrm{s}^{-1}\right)$ & $6.48 \pm 0.38$ & $6.89 \pm 0.49$ & 6.69 & 0.04 & 0.94 \\
\hline Average speed $\left(\mathrm{m} \mathrm{s}^{-1}\right)$ & $5.96 \pm 0.21$ & $6.28 \pm 0.26$ & 5.75 & 0.01 & 1.34 \\
\hline Minimum speed $\left(\mathrm{m} \mathrm{s}^{-1}\right)$ & $5.53 \pm 0.32$ & $5.87 \pm 0.23$ & 5.78 & 0.01 & 1.20 \\
\hline \multicolumn{6}{|l|}{ Aerobic parameters } \\
\hline $\operatorname{SRT}_{20}\left(\mathrm{~km} \mathrm{~h}^{-1}\right)$ & $9.92 \pm 1.71$ & $10.67 \pm 1.30$ & 10.73 & 0.01 & 0.49 \\
\hline$V \mathrm{O}_{2 \max }\left(\mathrm{mL} \mathrm{kg}^{-1} \min ^{-1}\right)$ & $46.99 \pm 7.02$ & $49.08 \pm 6.08$ & 6.92 & 0.01 & 0.31 \\
\hline \multicolumn{6}{|l|}{ Agility } \\
\hline SRT (s) & $10.05 \pm 0.32$ & $9.67 \pm 0.30$ & -3.92 & 0.01 & 1.22 \\
\hline
\end{tabular}

$T 1$ assessment before the training period, $T 2$ assessment after the training period, $P C$ percentage change, $B M I$ body mass index, $E F$ effect size, $S R T_{20}$ multistage $20 \mathrm{~m}$ shuttle run test, $S R T$ shuttle run test

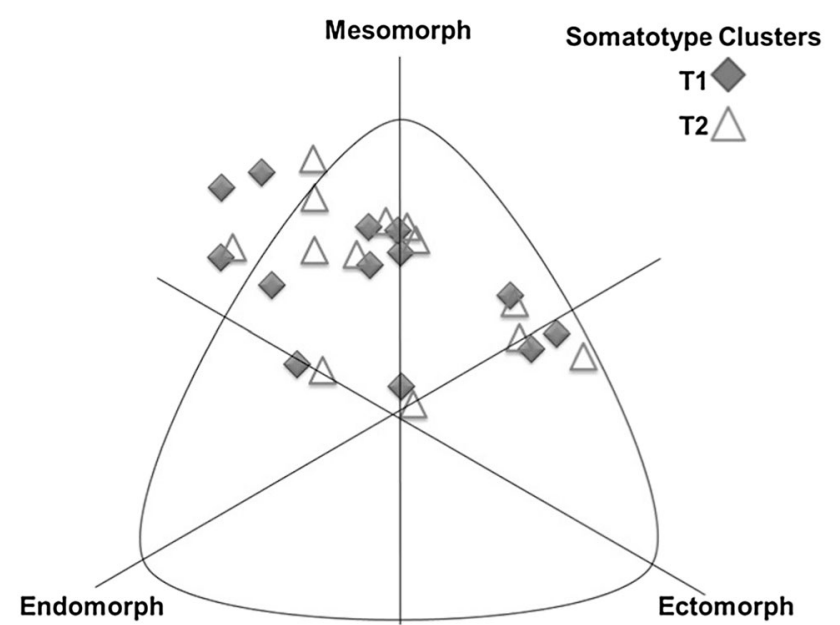

Fig. 2 Distribution of the subjects in the somatotype clusters for the training periods $\mathrm{T} 1$ and $\mathrm{T} 2$

specific periods of futsal training. Cyrino and colleagues [28] found an increase of $2.7 \%$ in the lean mass of young futsal athletes after 24-week of specific training. However, the literature does not clear about changes in anthropometric parameters, particularly the percentage of fat in professional and semi-professional athletes. In the present study, no significant increase in lean body mass (1.6\%) was found; however, there was a significant decrease in body fat percentage $(-7.5 \%)$, although insufficient to lead to significant changes in the somatotype profile of this sample. Nevertheless, this is an important result, since a reduction in adipose tissue may contribute to improvement in sports performance $[6,29]$. In general, the changes in anthropometric variables were only discrete, signaling that futsal specific training is not the best strategy for positive changes in anthropometric variables, and, in a practical context, more specific interventions would be needed for this purpose. It is also worth mentioning that nutritional aspects were not analyzed in this study, and these can directly influence body composition.

Regarding the aerobic parameters, the 12-week futsal training during the competitive period was able to improve the aerobic capacity of semi-professional futsal athletes. Milioni and colleagues [12] found no significant differences in the aerobic capacity of adults and Under- 20 semiprofessional futsal players before and after 6 weeks of specific futsal training. However, Freitas and colleagues [30] showed a significant increase of approximately $6.7 \%$ in the aerobic performance of elite futsal athletes after 14 weeks of training; in the present study, an increase of $6.9 \%$ in the $V \mathrm{O}_{2 \max }$ was found after 12-week of specific training. Comparing the average and total internal load in 
each mesocycle of the study by Freitas and colleagues [30] with the average external load in each mesocycle of the present study, similarities both in behavior over time (Fig. 1) and absolute values can be noted, indicating that the proposed loads and training period can significantly increase the $V \mathrm{O}_{2 \max }$ in futsal players. After the training period, the level of $V \mathrm{O}_{2 \max }$ achieved got closer to oxygen uptake level during simulated futsal game verified by Castagna et al. [3]. Corroborating these findings, Milanez et al. [31] found a significant correlation $(r=-0.75)$ between the $V \mathrm{O}_{2 \max }$ values and accumulated internal load of 4 weeks of training in professional futsal players. The negative relationship found by Milanez et al. [31] (i.e., the higher $V \mathrm{O}_{2 \max }$, the lower RPE) makes clear the necessity to improve aerobic power in futsal athletes aiming to attenuate the RPE during the training sessions and games, thus collaborating with better performances.

In addition, in the present study, a significant improvement in repeated sprint parameters was verified, an important factor since futsal players perform high intensity running for 5-12\% of a match [7]. Soares-Caldeira et al. [4] did not find any improvement in repeated sprint performance during the 4 weeks of pre-season; however, Oliveira et al. [6] verified an improvement in repeated sprint performance during the pre-season and maintenance during the competition period. The enhancement in anaerobic power and maximal speed indicates an improved performance in the futsal players in decisive moments of the match, such as scoring a goal. Changes in anaerobic power (an improvement of 6-25\%) were a result of improvements in both anaerobic and aerobic capacity $[4$, 32], which facilitates recovery during, repeated sprints. Corroborating these results, Alizadeh et al. [33] and KalvaFilho et al. [34] found a positive correlation between the relative intensity of the $V \mathrm{O}_{2 \max }$ and performance in repeated sprints in football players. Thus, due to metabolic demand in futsal, the development of anaerobic power seems to play an important role to performance during the match; therefore, a good periodization for the specific training could be essential for this purpose. Vieira et al. [35] after to compare differences between a friendly preseason match and an official in-season match regarding physical, technical, and organizational performances of a professional Brazilian futsal team, values obtained for distance covered per minute, percentage of distance covered at moderate intensity, team coverage area, spread, passes, possessions, ball touches, and successful passes per minute were greater for the official in-season match than friendly pre-season match, highlighting that after a long period of training and competitions, the team exhibited enhanced tactical and technical performances, along with enhanced physical performance, indicating a need for a good periodization during the season.
Despite the important and innovative results, this study has some limitations. The tests used are indirect measures of aerobic and anaerobic parameters, which could limit the results. However, the protocols used are easy to apply, simplifying their application during training without interfering in the periodization. In addition, the protocols are widely used in sports and, in general, present high reliability [13, 19, 22-24]. Thus, we consider the utilization of the proposed tests to be viable. The sample consisted of semi-professional players, which does not devalue the findings, but generates doubt for professional athletes of the sport. As a result, we recommend the study be replicated in professional futsal players. Finally, the load control was only external, which may generate doubts related to its control over the internal response of the athletes. However, our results suggest that the proposal for planning by monitoring external load is effective in enhancing performance in semi-professional futsal players.

Based on the findings, it can be concluded that the proposed 12-week training plan was able to significantly improve the agility and aerobic and anaerobic capacity of semi-professional futsal players. However, although relevant, the findings related to body composition were only discrete, specific intervention strategies being required to change this component. Thus, this training model is recommended for futsal players during the competition period.

\section{Compliance with ethical standards}

Conflict of interest The authors declare that they have no conflict of interest.

Ethical approval All procedures performed in studies involving human participants were in accordance with the ethical standards of the Ethical Committee of UNESP Universidade Estadual Paulista, (Ref. 7828) and with the 1964 Helsinki declaration and its later amendments or comparable ethical standards.

Informed consent Informed consent was obtained from all individual participants included in study.

\section{References}

1. Castagna C, Impellizzeri FM, Belardinelli R, Abt G, Coutts A et al (2006) Cardiorespiratory responses to Yo-Yo intermittent endurance test in non elite youth soccer players. J Strength Cond Res 20(2):326-330

2. Alvarez JC, D’Ottavio S, Vera JG, Castagna C (2009) Aerobic fitness in futsal players of different competitive level. J Strength Cond Res 23:2163-2166

3. Castagna C, D'Ottavio S, Vera JG, Barbero-Alvarez JS (2009) Match demands of professional futsal: a case study. J Sci Med Sport 12(4):490-494

4. Soares-Caldeira LF, de Souza EA, de Freitas VH, de Moraes SM, Leicht AS et al (2014) Effects of additional repeated sprint training during preseason on performance, heart rate variability, and stress symptoms in futsal players: a randomized controlled trial. J Strength Cond Res 28(10):2815-2826 
5. Moreira A, de Moura NR, Coutts A, Costa EC, Kempton T et al (2013) Monitoring internal training load and mucosal immune responses in futsal athletes. J Strength Cond Res 27(5): 1253-1259

6. Oliveira RS, Leicht AS, Bishop D, Barbero-Álvarez JC, Nakamura FY (2013) Seasonal changes in physical performance and heart rate variability in high level futsal players. Int J Sports Med 34(5):424-430

7. Barbero-Alvarez JC, Soto VM, Granda J (2008) Match analysis and heart rate of futsal players during competition. J Sports Sci 26(1):63-73

8. Gorostiaga EM, Llodio I, Ibánez J, Granados C, Navarro I et al (2009) Differences in physical fitness among indoor and outdoor elite male soccer players. Eur J Appl Physiol 106(4):483-491

9. Doğramaci SN, Watsford ML (2006) A comparison of two different methods for time-motion analysis in team sports. Int $\mathbf{J}$ Perform Anal Sport 6(1):73-83

10. Miranda REEPC, Antunes HKM, Pauli JR, Puggina EF, da Silva ASR (2013) Effects of 10-week soccer training program on anthropometric, psychological, technical skills and specific performance parameters in youth soccer players. Sci Sports 28(2):81-87

11. De Oliveira Bueno MJ, Caetano FG, Pereira TJ, De Souza NM et al (2014) Analysis of the distance covered by Brazilian professional futsal players during official matches. Sports Biomech. 13(3):230-240

12. Milioni F, Barbieri RA, Silva ASR, Santiago PRP, Mendes OC et al (2013) Avaliação de parâmetros de treinamento provenientes de teste indireto em atletas de futsal sub20 e adulto. Pensar Prát (Online) 16:1146-1158

13. Zagatto AM, Beck WR, Gobatto CA (2009) Validity of the running anaerobic sprint test for assessing anaerobic power and predicting short-distance performances. J Strength Cond Res 23:1820-1827

14. Johnson BL, Nelson JK (1979) Practical measurement for evaluation in physical education. Burgess, Minneapolis

15. Léger LA, Mercier D, Gadoury C, Lambertz J (1988) The multistage 20 meters shuttle run test for aerobic fitness. J Sports Sci 6:93-101

16. Jackson AS, Pollock ML, Ward A (1980) Generalized equations for predicting body density of women. Med Sci Sports Exerc $12: 175-182$

17. Heath BH, Carter JEL (1967) A modified somatotype method. Am J Phys Anthropol 27:57-74

18. Ross WD, Marfell-Jones MJ (1982) Kinan- thropometry. In: Macdougall JD, Wenger HA, Green HJ (eds) Physiological testing of the elite athlete. Movement Publications, New York, pp 75-115

19. Damon A, Bleibtreu HK, Elliot O, Giles E (1962) Predicting somatotype from body measurements. Am J Phys Anthropol 20(4):461-474

20. Zacharogiannis EPG, Tziortzis S (2006) An evaluation of tests of anaerobic power and capacity. Med Sci Sports Exerc 36(5):S116
21. Metsiosa GS, Flouris AD, Koutedakis Y, Nevill A (2008) Criterion-related validity and test-retest reliability of the $20 \mathrm{~m}$ square shuttle test. J Sci Med Sport. 11(2):214-217

22. Duarte M, Duarte C (2001) Validity of the maximal multistage 20 m shuttle run test. Braz J Sci Mov 9(3):7-14

23. Ortega FB, Artero EG, Ruiz JR, Vicente-Rodriguez G, Bergman $P$ et al (2008) Reliability of health-related physical fitness tests in European adolescents. The HELENA Study. Int J Obes (Lond) 32(5):S49-S57

24. Vicente-Rodríguez G, Rey-López JP, Ruíz JR, Jiménez-Pavón D, Bergman $P$ et al (2011) Interrater reliability and time measurement validity of speed-agility field tests in adolescents. J Strength Cond Res 25(7):2059-2063

25. Foster C (1998) Monitoring training in athletes with reference to overtraining syndrome. Med Sci Sports Exerc 30:1164-1168

26. Avelar A, dos Santos KM, Cyrino ES, Carvalho FO, Dias RMR et al (2008) Anthropometric and motor performance profile of elite futsal athletes. Braz J Kinanthropometry Hum Perform 10(1):76-80

27. Leal Junior ECP, Souza FB, Magini M, Martins RABL (2007) Comparative study of the oxygen consumption and anaerobic threshold in a progressive exertion test in professional soccer and indoor soccer athletes. Braz J Sports Med 12:323-326

28. Cyrino ES, Altimari LR, Okano AH, Coelho CF (2002) Effects of futsal training on the body composition and motor performance of young athletes. Braz J Kinanthropometry Hum Perform 10:41-46

29. Buchheit M, Simpson BM, Mendez-Villanueva A (2013) Repeated high-speed activities during youth soccer games in relation to changes in maximal sprinting and aerobic speeds. Int J Sports Med 34(1):40-48

30. Freitas VH, Miloski B, Bara Filho MG (2012) Quantification of training load using session RPE method and performance in futsal. Braz J Kinanthropometry Hum Perform 14(1):73-82

31. Milanez VF, Pedro RE, Moreira A, Boullosa DA, Salle-Neto F et al (2011) The role of aerobic fitness on session rating of perceived exertion in futsal players. Int J Sports Physiol Perform 6(3):358-366

32. Bangsbo J, Iaia FM, Krustrup P (2008) The Yo-Yo intermittent recovery test: a useful tool for evaluation of physical performance in intermittent sports. Sports Med 38(1):37-51

33. Alizadeh R, Hovanloo F, Safania AM (2010) The relationship between aerobic power and repeated sprint ability in young soccer players with different levels of $V \mathrm{O}_{2 \max }$. J Phys Educ Sport 27:86-92

34. Kalva-Filho CA, Loures JP, Franco VH, Kaminagakura EI, Zagatto A et al (2013) Relationship between aerobic parameters and intermittent high-intensity effort performance. Motriz 9(2):306-312

35. Vieira LHP, Doğramaci SN, Barbieri RA, Milioni F, Moura FA et al (2016) Preliminary results on organization on the court, physical and technical performance of Brazilian professional futsal players: comparison between friendly pre-season and official match. Motriz 22(2):79-91 